\title{
Lowering of blood pressure after nitrate-rich vegetable consumption is abolished with the co-ingestion of thiocyanate-rich vegetables in healthy normotensive males
}

Rebecca Dewhurst-Trigg ${ }^{\text {ab* }^{*}}$, Toby Yeates ${ }^{\mathrm{a}^{*}}$, Jamie R. Blackwell ${ }^{\mathrm{a}}$, Christopher Thompson a, Adam Linoby ${ }^{\mathrm{a}}$, Paul T. Morgan ${ }^{\mathrm{a}}$, Ida Clarke $^{\mathrm{a}}$, Luke J. Connolly ${ }^{\mathrm{a}}$, Lee J. Wylie, Paul G. Winyard ${ }^{\mathrm{c}}$, Andrew M. Jones ${ }^{\mathrm{a}}$ and Stephen J. Bailey ${ }^{\text {ab }}$

${ }^{\text {a }}$ Sport and Health Sciences, College of Life and Environmental Sciences, St. Luke's Campus, University of Exeter, Heavitree Road, Exeter, UK. ${ }^{\text {b }}$ School of Sport, Exercise and Health Sciences, Loughborough University, Ashby Road, Loughborough, UK. ' University Exeter Medical School, St. Luke’s Campus, University of Exeter, Heavitree Road, Exeter, UK. * These authors contributed equally towards this work.

Address for Correspondence:

Stephen J Bailey, Ph.D.

E-mail: $\underline{\text { S.Bailey2@lboro.ac.uk }}$

School of Sport, Exercise and Health Sciences

Loughborough University

Ashby Road

Loughborough

Leicestershire LE11 3TU

Tel: +44 (0) 1509226433

Fax: +44 (0) 150922630 


\section{ABSTRACT}

A diet rich in vegetables is known to provide cardioprotection. However, it is unclear how the consumption of different vegetables might interact to influence vascular health. This study tested the hypothesis that nitrate-rich vegetable consumption would lower systolic blood pressure but that this effect would be abolished when nitrate-rich and thiocyanate-rich vegetables are co-ingested. On four separate occasions, and in a randomised cross-over design, eleven healthy males reported to the laboratory and consumed a $750 \mathrm{~mL}$ vegetable smoothie that was either: low in nitrate $(\sim 0.3 \mathrm{mmol})$ and thiocyanate $(\sim 5 \mu \mathrm{mol})$, low in nitrate and high in $\mathrm{SCN}^{-}(\sim 72 \mu \mathrm{mol})$, high in nitrate $(\sim 4 \mathrm{mmol})$ and low in $\mathrm{SCN}^{-}$and high in nitrate and $\mathrm{SCN}^{-}$. Blood pressure as well as plasma and salivary [thiocyanate], [nitrate] and [nitrite] were assessed before and 3 hours after smoothie consumption. Plasma [nitrate] and [nitrite] and salivary [nitrate] were not different after consuming the two high-nitrate smoothies, but salivary [nitrite] was higher after consuming the high-nitrate low-thiocyanate smoothie $(1183 \pm 625 \mu \mathrm{M})$ compared to the high-nitrate high-thiocyanate smoothie $(941 \pm$ $532 \mu \mathrm{M} ; P<0.001)$. Systolic blood pressure was only lowered after consuming the highnitrate low-thiocyanate smoothie $(-3 \pm 5 \mathrm{mmHg} ; P<0.05)$. The acute consumption of vegetables high in nitrate and low in thiocyanate lowered systolic blood pressure. However, when the same dose of nitrate-rich vegetables was co-ingested with thiocyanate-rich vegetables the increase in salivary [nitrite] was smaller and systolic blood pressure was not lowered. These findings might have implications for optimising dietary guidelines aimed at improving cardiovascular health.

Key Words: Entero-salivary circulation; nitrite; nitric oxide; vascular health; nutrition 


\section{INTRODUCTION}

Cardiovascular disease (CVD) is the leading cause of mortality globally and places a significant burden on healthcare services [1]. In an effort to attenuate CVD morbidity costeffectively, many governments actively promote the consumption of a diet rich in fruit and vegetables [2-4] based on evidence that adhering to such diets can mitigate the risks associated with CVD morbidity [5,6]. However, emerging evidence indicates that the cardioprotective effect afforded by vegetable consumption outweighs that of fruit consumption [7], and that leafy green vegetables rich in inorganic nitrate $\left(\mathrm{NO}_{3}^{-}\right)$might be particularly effective at improving the health of the cardiovascular system [8-10,11].

The cardiovascular benefits associated with $\mathrm{NO}_{3}{ }^{-}$-rich vegetable consumption has been ascribed to the stepwise reduction of $\mathrm{NO}_{3}{ }^{-}$to nitrite $\left(\mathrm{NO}_{2}{ }^{-}\right)$and then nitric oxide (NO) [12]. Since humans have a limited capacity to directly reduce $\mathrm{NO}_{3}{ }^{-}$to $\mathrm{NO}_{2}^{-}$, with this being critically dependent on the $\mathrm{NO}_{3}{ }^{-}$reducing bacteria on the tongue [13,14], a rate limiting step for the chemical reduction of $\mathrm{NO}_{3}{ }^{-}$is the delivery of $\mathrm{NO}_{3}{ }^{-}$to the oral cavity through the enterosalivary circulation [15]. The uptake of $\mathrm{NO}_{3}{ }^{-}$into the salivary glands occurs in competition with other anions, including thiocyanate $\left(\mathrm{SCN}^{-}\right)$, with evidence that $\mathrm{SCN}^{-}$has a higher affinity for transport into the salivary glands compared to $\mathrm{NO}_{3}{ }^{-}[16]$. It has recently been reported that cigarette smokers, who manifest higher plasma and salivary [SCN${ }^{-}$, exhibited smaller increases in salivary $\left[\mathrm{NO}_{3}^{-}\right]$and plasma $\left[\mathrm{NO}_{2}{ }^{-}\right]$compared to non-smokers after ingesting the same $\mathrm{NO}_{3}{ }^{-}$dose, and that blood pressure was only lowered post $\mathrm{NO}_{3}{ }^{-}$ supplementation in the non-smokers [17]. Therefore, increased exposure to $\mathrm{SCN}^{-}$has the potential to perturb dietary $\mathrm{NO}_{3}{ }^{-}$metabolism and its beneficial effect on vascular health. 
Although some green vegetables, including spinach and rocket, are a rich source of $\mathrm{NO}_{3}{ }^{-}$ $[18,19]$, other green vegetable varieties, including members of the Brassica family such as cabbage, cauliflower and broccoli, have been reported to increase serum [SCN$\left.{ }^{-}\right]$[20]. Brassica vegetables are rich in glucosinolates [21,22]. During processes that damage plant cell membranes, such as mastication, glucosinolates are exposed to myrosinase which catalyses the hydrolysis of glucosinolates to $\mathrm{SCN}^{-}[23,24]$. Therefore, co-ingestion of glucosinolate/SCN${ }^{-}$-rich vegetables with $\mathrm{NO}_{3}{ }^{-}$-rich vegetables has the potential to perturb dietary $\mathrm{NO}_{3}{ }^{-}$metabolism and the beneficial effect of $\mathrm{NO}_{3}{ }^{-}$on vascular health markers.

The purpose of this study was therefore to investigate the independent and combined effect of ingesting $\mathrm{NO}_{3}{ }^{-}$-rich and $\mathrm{SCN}^{-}$-rich vegetables on dietary $\mathrm{NO}_{3}{ }^{-}$metabolism and blood pressure at doses within the recommended daily fruit and vegetable intake of $400 \mathrm{~g} \cdot \mathrm{day}^{-1}[3,25]$. We hypothesised that, compared to the ingestion of vegetables high in $\mathrm{NO}_{3}{ }^{-}$and low in $\mathrm{SCN}^{-}$, the

increases in salivary $\left[\mathrm{NO}_{3}^{-}\right]$and $\left[\mathrm{NO}_{2}^{-}\right]$and plasma $\left[\mathrm{NO}_{2}^{-}\right]$would be blunted, and the lowering of blood pressure would be attenuated when the same dose of $\mathrm{NO}_{3}{ }^{-}$-rich vegetables was coingested with $\mathrm{SCN}^{-}$-rich vegetables. We also hypothesised that the ingestion of vegetables low in $\mathrm{NO}_{3}{ }^{-}$would not alter blood pressure, irrespective of their $\mathrm{SCN}^{-}$content, due to a lack of change in plasma $\left[\mathrm{NO}_{2}^{-}\right]$.

\section{SUBJECTS AND METHODS}

\subsection{Subjects characteristics}

Eleven healthy, non-smoking males (mean \pm SD, age $21 \pm 1 \mathrm{yr}$, height $1.82 \pm 0.03 \mathrm{~m}$, body mass $80 \pm 9 \mathrm{~kg}$ ) were recruited from the University student community to participate in this trial. The participant number was determined a priori via a statistical power calculation. 
Specifically, to detect an effect size of 1 , which was based on the peak reduction in systolic blood pressure following the ingestion of $\mathrm{NO}_{3}{ }^{-}$-rich beetroot juice providing 4 mmol $\mathrm{NO}_{3}{ }^{-}$ from the study by Wylie et al. [26], with a high statistical power (0.80) and an $\alpha$ error probability of $0.05,10$ subjects were required. We recruited 11 participants to account for potential participant drop out. This calculation was conducted using G*Power (Version 3.1.9.2). All procedures employed in this study were approved by the Institutional Research Ethics Committee. Subjects gave their written informed consent to participate in this trial prior to the commencement of the study and after the experimental procedures, associated risks, and potential benefits of participation had been explained. Subjects were instructed to arrive at each laboratory testing session in a rested state after an overnight fast. Since the chemical reduction of $\mathrm{NO}_{3}{ }^{-}$to $\mathrm{NO}_{2}{ }^{-}$in the oral cavity is thwarted by antibacterial mouthwash [13], subjects were required to refrain from mouthwash use for the duration of the study. Each subject was also asked to avoid consumption of $\mathrm{NO}_{3}{ }^{-}$-rich and glucosinolate/SCN${ }^{-}$-rich foods for $48 \mathrm{~h}$, and from caffeine and alcohol ingestion 12 and $24 \mathrm{~h}$ before each test, respectively. All subjects were instructed to maintain their habitual physical activity pattern for the duration of the study, and to avoid strenuous exercise in the $24 \mathrm{~h}$ preceding the testing sessions. All tests were performed at the same time of day ( \pm 1 hour).

\subsection{Experimental design}

Subjects were required to report to the laboratory on five occasions over a 3-5 week period to complete the experimental testing. Since environmental (e.g. humidity, temperature, water content and exposure to sunlight) and agricultural factors can influence vegetable $\mathrm{NO}_{3}{ }^{-}$and $\mathrm{SCN}^{-}$concentrations $[19,22,27,28]$, each vegetable was obtained from the same supplier (Tesco Stores Ltd, UK) and the trial was completed within a 4-month period to limit the potential for variability in these factors. 
On the first visit to the laboratory, subjects were familiarized with the blood pressure measures and venous blood and saliva collection methods described below. On the subsequent four laboratory visits, seated blood pressure was assessed, and saliva and venous blood samples were obtained, after arrival at the laboratory. Subjects then consumed a vegetable smoothie beverage prepared using vegetables either low in $\mathrm{NO}_{3}{ }^{-}$and $\mathrm{SCN}^{-}$(LoNLoT); low in $\mathrm{NO}_{3}{ }^{-}$, high in $\mathrm{SCN}^{-}(\mathrm{LoN}-\mathrm{HiT})$; high in $\mathrm{NO}_{3}{ }^{-}$, low in $\mathrm{SCN}^{-}$(HiN-LoT); or high in $\mathrm{NO}_{3}{ }^{-}$and $\mathrm{SCN}^{-}(\mathrm{HiN}-\mathrm{HiT})$ along with a standardised breakfast of $54 \mathrm{~g}$ of porridge oats (“Oats So Simple”, Quaker Oats) prepared with $180 \mathrm{~mL}$ of tap water and one 20 g sachet of golden syrup (Lyle's golden syrup). The smoothies were administered in a randomized, doubled-blind, counter-balanced, cross-over experimental design. Blood pressure was measured and venous blood and saliva were collected three hours post vegetable smoothie consumption to align with the peak plasma $\left[\mathrm{NO}_{2}^{-}\right]$and blood pressure reduction following dietary supplementation with $4.2 \mathrm{mmol} \mathrm{NO}_{3}^{-}$[26]. Plasma and salivary $\left.\left[\mathrm{NO}_{3}{ }^{-}\right], \mathrm{NO}_{2}{ }^{-}\right]$and $\left[\mathrm{SCN}^{-}\right]$were determined using the procedures described below. Subjects were naive to the experimental hypotheses and were informed that the aim of this study was to investigate the effects of consuming different vegetables on vascular health.

\subsection{Supplementation procedures}

To inform the composition of the vegetable smoothie beverages administered in this study, the $\mathrm{NO}_{3}{ }^{-}$and $\mathrm{SCN}^{-}$content of a variety of vegetables was assessed prior to experimental testing. These preliminary analyses revealed that garden peas were low in both $\mathrm{NO}_{3}{ }^{-}(\sim 0.8$ $\mathrm{mg} / 100 \mathrm{~g})$ and $\mathrm{SCN}^{-}(<0.1 \mathrm{mg} / 100 \mathrm{~g})$, spinach and rocket were high in $\mathrm{NO}_{3}{ }^{-}(\sim 143.0$ and $360.5 \mathrm{mg} / 100 \mathrm{~g}$, respectively) and low in $\mathrm{SCN}^{-}$(both $<0.1 \mathrm{mg} / 100 \mathrm{~g}$ ), and the inner leaves of a cabbage were high in $\mathrm{SCN}^{-}(\sim 5.0 \mathrm{mg} / 100 \mathrm{~g})$ and low in $\mathrm{NO}_{3}{ }^{-}(\sim 7.3 \mathrm{mg} / 100 \mathrm{~g})$. Therefore, 
these vegetables were selected to prepare the four vegetable smoothie beverages administered in this study. Further pilot work to assess drink palatability and the potential for side effects, including gastrointestinal (GI) discomfort, revealed that subjects were able to ingest $750 \mathrm{~mL}$ of each of the four vegetable smoothie beverages prepared in this study with minimal GI discomfort.

The four vegetable smoothies administered in this study were all $750 \mathrm{~mL}$ and comprised 250 mL tap water, $150 \mathrm{~mL}$ of Ribena blackcurrant cordial (Ribena, Lucozade Ribena Suntory Limited, United Kingdom) and $340 \mathrm{~g}$ of blended green vegetables. The $340 \mathrm{~g}$ of green vegetables comprised 340 g garden peas in the LoN-LoT beverage; 122 g garden peas and $218 \mathrm{~g}$ inner cabbage leaves in the LoN-HiT beverage; 218 g garden peas, $87 \mathrm{~g}$ spinach and 35 g rocket in the HiN-LoT beverage; and $218 \mathrm{~g}$ inner cabbage leaves, $87 \mathrm{~g}$ spinach and $35 \mathrm{~g}$ rocket in the HiN-HiT beverage. Vegetables were weighed using digital scales sensitive to 100 mg (Ohaus Valor 3000 Xtreme, Ohaus Corporation, USA) and blended on the morning of testing. Each smoothie was then refrigerated at $4^{\circ} \mathrm{C}$ for $>15$ min prior to consumption. Vegetables were blended raw to preserve nutritional content, since conventional cooking methods reduce the intake of glucosinolates/ $\mathrm{SCN}^{-}$[22] and $\mathrm{NO}_{3}{ }^{-}$[29]. A $30 \mathrm{~mL}$ aliquot was obtained from each of the four vegetable smoothies from which subsequent $1.5 \mathrm{~mL}$ aliquots were collected and analyzed to determine the $\mathrm{NO}_{3}{ }^{-}$and $\mathrm{SCN}^{-}$content of the vegetable smoothie beverages (see below for further details). These analyses were completed at the start and end of the study to gauge any changes in the vegetable $\mathrm{NO}_{3}{ }^{-}$and $\mathrm{SCN}^{-}$content across the study. The $\mathrm{NO}_{3}{ }^{-}$and $\mathrm{SCN}^{-}$content of the four vegetable smoothie beverages at the start and end of the study are presented in table 1, with the mean of these two samples used to indicate the mean $\mathrm{NO}_{3}{ }^{-}$and $\mathrm{SCN}^{-}$contents of the beverages across the duration of the study. 


\subsection{Measurements}

\subsubsection{Blood pressure}

Subjects were required to rest seated for $10 \mathrm{~min}$ in an isolated temperature-controlled room. Thereafter, blood pressure of the brachial artery was measured whilst the subject was seated using an automated sphygmomanometer (Dinamap Pro, GE Medical Systems, Tampa, USA). Five measurements were taken and the mean of the five measurements was used for analysis.

\subsubsection{Blood and saliva collection}

Venous blood samples were drawn into $6 \mathrm{~mL}$ lithium-heparin tubes (Sarstedt, Leicester, UK). Samples were centrifuged at $4,000 \mathrm{rpm}$ and $4^{\circ} \mathrm{C}$ for $10 \mathrm{~min}$, within $1 \mathrm{~min}$ of collection. Plasma was subsequently extracted and immediately frozen at $-80^{\circ} \mathrm{C}$ for later analysis of $\left[\mathrm{NO}_{3}{ }^{-}\right],\left[\mathrm{NO}_{2}^{-}\right]$and $\left[\mathrm{SCN}^{-}\right]$. Unstimulated saliva samples $(\sim 3 \mathrm{~mL})$ were collected into $30 \mathrm{~mL}$ universal containers and $1 \mathrm{~mL}$ aliquots were frozen at $-80^{\circ} \mathrm{C}$ for later analysis of $\left[\mathrm{NO}_{3}{ }^{-}\right]$, $\left[\mathrm{NO}_{2}^{-}\right]$and $\left[\mathrm{SCN}^{-}\right]$.

\subsection{Data analysis procedures}

\subsubsection{Plasma and salivary $\left[\mathrm{NO}_{3}^{-}\right]$and $\left[\mathrm{NO}_{3}^{-}\right]$determination}

All glassware, utensils, and surfaces were rinsed with deionized water to remove residual NO intermediates prior to $\left[\mathrm{NO}_{3}{ }^{-}\right]$and $\left[\mathrm{NO}_{2}^{-}\right]$analysis. Plasma samples were deproteinized using zinc sulfate $\left(\mathrm{ZnSO}_{4}\right)$ /sodium hydroxide $(\mathrm{NaOH})$ precipitation prior to determination of $\left[\mathrm{NO}_{3}{ }^{-}\right.$ ]. Firstly, $500 \mu \mathrm{L}$ of $0.18 \mathrm{~N} \mathrm{NaOH}$ was added to $100 \mu \mathrm{L}$ of sample followed by a 5 min incubation at room temperature. Subsequently, samples were treated with $300 \mu \mathrm{L}$ of aqueous $\mathrm{ZnSO}_{4}(5 \% \mathrm{w} / \mathrm{v})$ and vortexed for 30 seconds before undergoing an additional $10 \mathrm{~min}$ incubation period at room temperature. Samples were then centrifuged at 4,000 rpm for 5 min, and the supernatant was removed for subsequent analysis. The $\left[\mathrm{NO}_{3}{ }^{-}\right]$of the 
deproteinized plasma sample was determined by its reduction to NO in the presence of $0.8 \%$ (w/v) vanadium chloride $\left(\mathrm{VCl}_{3}\right)$ in $1 \mathrm{M} \mathrm{HCl}$ within an air-tight purging vessel. Plasma samples were introduced to the vessel via $50 \mathrm{uL}$ injections into the septum at the top of the vessel. The spectral emission of electronically excited nitrogen dioxide, derived from the reaction of NO with ozone, was detected by a thermoelectrically cooled, red-sensitive photomultiplier tube housed in a Sievers gas-phase chemiluminescence nitric oxide analyzer (Sievers NOA 280i, Analytix Ltd, Durham, UK). The $\left[\mathrm{NO}_{3}{ }^{-}\right]$was determined by plotting signal $(\mathrm{mV})$ area against a calibration plot of sodium nitrate standards. The $\left[\mathrm{NO}_{2}{ }^{-}\right]$of the undiluted (non-deproteinized) plasma was determined by its reduction to NO in the presence of glacial acetic acid and aqueous sodium iodide $(4 \% \mathrm{w} / \mathrm{v})$. Sodium nitrite standards were used. Injections of $100 \mathrm{uL}$ of plasma were used for $\left[\mathrm{NO}_{2}{ }^{-}\right]$determination. After thawing at room temperature, saliva samples were centrifuged for $10 \mathrm{~min}$ at $14000 \mathrm{rpm}$ and the supernatant was removed for subsequent analysis. The supernatant was diluted 100-fold with deionized water and $\left[\mathrm{NO}_{3}{ }^{-}\right]$and $\left[\mathrm{NO}_{2}{ }^{-}\right]$were determined from $50 \mathrm{uL}$ injections, using the same reagents describe above for the plasma analyses.

\subsubsection{Plasma and salivary [SCN] determination}

Plasma and salivary $\left[\mathrm{SCN}^{-}\right]$were measured in duplicate using the procedures described by Tsuge et al. [30]. Briefly, $300 \mu \mathrm{L}$ of plasma was treated with $200 \mu \mathrm{L}$ of trichloroacetic acid $(25 \% \mathrm{w} / \mathrm{v})$ and centrifuged for $10 \mathrm{~min}$ at $14000 \mathrm{rpm}$. The supernatant was then removed for subsequent analysis. $50 \mu \mathrm{L}$ of sample, $15 \mu \mathrm{L}$ of $1 \mathrm{M}$ of ice-cold potassium hydrogen phosphate solution ( $\mathrm{pH} 5.5$ ), $5 \mu \mathrm{L}$ of $5 \mathrm{M} \mathrm{NaOH}$ solution, and $10 \mu \mathrm{L}$ of $6.25 \mathrm{mg} / \mathrm{ml}$ chloramine T solution were added to a 96-well microtiter plate (Sterilin Ltd., Caerphilly, UK) and incubated on ice for $2 \mathrm{~min}$. Subsequently, $120 \mu \mathrm{L}$ of cyanoline blue solution $(0.27 \%$ $\mathrm{w} / \mathrm{v}$ ) was added to the microtiter plate and the plate was incubated for $20 \mathrm{~min}$ at room 
temperature. Following incubation, sample absorbance was measured at $620 \mathrm{~nm}$ using a microplate reader (EnSpire 2300, Perkin Elmer, Hamburg, Germany). Thawed saliva samples were centrifuged for $10 \mathrm{~min}$ at $14000 \mathrm{rpm}$ and the supernatant was removed for subsequent analysis. Samples were diluted 25 fold, and $40 \mu \mathrm{L}$ of the diluted sample was added to a 96well microtiter plate in addition to $20 \mu \mathrm{L}$ of $1 \mathrm{M}$ potassium phosphate buffer solution and 20 $\mu \mathrm{L}$ of $6.25 \mathrm{mg} / \mathrm{ml}$ choramine $\mathrm{T}$ solution, and incubated on ice for $2 \mathrm{~min}$. Cyanoline blue solution (140 $\mu \mathrm{L} 0.27 \% \mathrm{w} / \mathrm{v}$ in pyridine-water, 1:5, v/v) was added to the microtiter plate followed by a 20 min incubation at room temperature. Following incubation, sample absorbance was measured at $620 \mathrm{~nm}$ using a microplate reader.

\subsubsection{Vegetable smoothie beverage $\left[\mathrm{NO}_{3}^{-}\right]$and $\left[\mathrm{SCN}^{-}\right]$determination}

Prior to analysis of the vegetable smoothie beverage $\mathrm{NO}_{3}{ }^{-}$content, a $1.5 \mathrm{~mL}$ aliquot of each vegetable smoothie beverage was transferred to a heat-resistant microcentrifuge tube. Subsequently, samples were heated at $130^{\circ} \mathrm{C}$ for 60 min using a heat plate (Grant QBD2, Cambridge, UK) to disintegrate the cell membranes for release of intracellular $\mathrm{NO}_{3}{ }^{-}$. Samples were then centrifuged at $12,000 \mathrm{~g}$ and $4^{\circ} \mathrm{C}$ for $8 \mathrm{~min}$ and the supernatant was removed for subsequent analysis. The supernatant was diluted 100 -fold with deionized water and $\left[\mathrm{NO}_{3}{ }^{-}\right]$was determined from $50 \mu \mathrm{L}$ injections using the same reagents and procedures described above for plasma $\left[\mathrm{NO}_{3}{ }^{-}\right]$analysis.

For determination of the vegetable smoothie beverage $\mathrm{SCN}^{-}$content, a $1.5 \mathrm{~mL}$ aliquot of each vegetable smoothie beverage was transferred to a standard microcentrifuge tube. These samples were not heated, as it was necessary to avoid the denaturation of the enzyme, myrosinase, which hydrolyzes glucosinolates to $\mathrm{SCN}^{-}$[22]. Vegetable smoothie samples were centrifuged at $12,000 \mathrm{~g}$ and $4^{\circ} \mathrm{C}$ for $10 \mathrm{~min}$ and the supernatant was removed for 
subsequent analysis. The [SCN$\left.{ }^{-}\right]$of the supernatant was determined using the same reagents and procedures described above for salivary [SCN$\left.{ }^{-}\right]$analysis.

\subsection{Statistical analysis}

A two-way (supplement $\times$ time) repeated-measures ANOVA was employed to assess pre-post supplement changes in blood pressure variables and plasma and salivary $\left[\mathrm{NO}_{3}^{-}\right],\left[\mathrm{NO}_{2}^{-}\right]$and $\left[\mathrm{SCN}^{-}\right]$for the four vegetable smoothie beverages administered in this study (LoN-LoT, LoNHiT, HiN-LoT and HiN-HiT). Where the ANOVA revealed significant differences, Fishers Least Significant Difference tests were employed to determine the origin of such effects. Pearson's product moment correlation coefficient was used to assess the relationship between changes in variables across conditions. All data are presented as mean \pm SD unless otherwise indicated. Statistical significance was accepted when $P<0.05$. All statistical analyses were conducted using IBM SPSS Statistics version 23.

\section{RESULTS}

Participants self-reported that their diet and exercise patterns were consistent for the 48 hours preceding each laboratory visit.

\subsection{Plasma and salivary [SCN$\left.{ }^{-}\right]$}

The plasma and salivary [SCN$\left.{ }^{-}\right]$across the four experimental conditions are illustrated in figure 1 . There was a significant supplement $\times$ time interaction effect for plasma and salivary [SCN${ }^{-}$] (both $P<0.001$ ). Compared to the pre-supplementation values, plasma [SCN${ }^{-}$] was higher in the LoN-HiT (12 \pm 4 vs. $20 \pm 7 \mu \mathrm{M})$ and HiN-HiT $(11 \pm 4$ vs. $20 \pm 6 \mu \mathrm{M})$ conditions $(P<0.01)$, but not different in the LoN-LoT $(16 \pm 6$ vs. $15 \pm 8 \mu \mathrm{M})$ and HiN-LoT (16 \pm 5 vs. $17 \pm 7 \mu \mathrm{M})$ conditions ( $P>0.05$; Figure 1$)$. Likewise, compared to the pre- 
supplementation values, salivary $\left[\mathrm{SCN}^{-}\right]$was higher post smoothie consumption in the LoNHiT $(1061 \pm 377$ vs. $1463 \pm 378 \mu \mathrm{M})$ and HiN-HiT $(976 \pm 519$ vs. $1286 \pm 393 \mu \mathrm{M})$ conditions $(P<0.01)$, but not different in the LoN-LoT $(1219 \pm 495$ vs. $1176 \pm 575 \mu \mathrm{M})$ and lower in the HiN-LoT (1283 \pm 485 vs. $922 \pm 368 \mu \mathrm{M})$ conditions $(P>0.05$; Figure 1$)$.

\subsection{Plasma and salivary $\left[\mathrm{NO}_{3}^{-}\right]$and $\left[\mathrm{NO}_{2}^{-}\right]$}

The plasma and salivary $\left[\mathrm{NO}_{3}{ }^{-}\right]$and $\left[\mathrm{NO}_{2}^{-}\right]$across the four experimental conditions are illustrated in figure 2. There were significant supplement $\times$ time interaction effects for plasma and salivary $\left[\mathrm{NO}_{3}{ }^{-}\right]$and $\left[\mathrm{NO}_{2}^{-}\right] \quad(P<0.001$ for all comparisons $)$. The postsupplementation plasma $\left[\mathrm{NO}_{3}{ }^{-}\right]$was higher than the pre-supplementation values in the $\mathrm{HiN}$ LoT (44 \pm 24 vs. $276 \pm 62 \mu \mathrm{M})$ and HiN-HiT (42 \pm 13 vs. $257 \pm 54 \mu \mathrm{M})$ conditions $(P<0.001)$, but not the LoN-LoT (44 \pm 30 vs. $41 \pm 20 \mu \mathrm{M})$ and LoN-HiT (42 \pm 17 vs. $41 \pm 14$ $\mu \mathrm{M})$ conditions $(P>0.05$; Figure 2$)$. Moreover, the post-supplementation plasma $\left[\mathrm{NO}_{3}{ }^{-}\right]$ values were higher in the HiN-LoT and HiN-HiT conditions compared to both the LoN-LoT and LoN-HiT conditions $(P<0.001)$, but were not different between the HiN-LoT and HiNHiT conditions $(P>0.05)$. Salivary $\left[\mathrm{NO}_{3}{ }^{-}\right]$was higher post-supplementation compared to presupplementation in the HiN-LoT $(513 \pm 705$ vs. $3114 \pm 2110 \mu \mathrm{M})$ and HiN-HiT (382 \pm 525 vs. $3362 \pm 2232 \mu \mathrm{M})$ conditions $(P<0.001)$, but not the LoN-LoT $(445 \pm 438$ vs. $403 \pm 387$ $\mu \mathrm{M})$ and LoN-HiT (428 \pm 375 vs. $315 \pm 252 \mu \mathrm{M})$ conditions $(P>0.05$; Figure 2$)$. The postsupplementation salivary $\left[\mathrm{NO}_{3}{ }^{-}\right]$values were also higher in the HiN-LoT and HiN-HiT conditions compared to both the LoN-LoT and LoN-HiT conditions $(P<0.001)$, but were not different between the HiN-LoT and HiN-HiT conditions $(P>0.05)$. The change in the pre-topost-supplementation plasma and salivary $\left[\mathrm{NO}_{3}{ }^{-}\right]$were not different between the HiN-LoT and HiN-HiT conditions $(P>0.05)$. 
Post-supplementation plasma $\left[\mathrm{NO}_{2}^{-}\right]$was higher than the pre-supplementation values in the HiN-LoT (121 \pm 32 vs. $327 \pm 110 \mathrm{nM})$ and HiN-HiT (137 \pm 59 vs. $336 \pm 108 \mathrm{nM})$ conditions $(P<0.001)$, but not the LoN-LoT $(123 \pm 45$ vs. $115 \pm 40 \mathrm{nM})$ and LoN-HiT $(117 \pm 37$ vs. 123

$\pm 37 \mathrm{nM}$ ) conditions $(P>0.05$; Figure 2$)$. The post-supplementation plasma $\left[\mathrm{NO}_{2}^{-}\right]$values were higher in the HiN-LoT and HiN-HiT conditions compared to both the LoN-LoT and LoN-HiT conditions $(P<0.001)$, but were not different between the HiN-LoT and HiN-HiT conditions $(P>0.05)$. Salivary $\left[\mathrm{NO}_{2}^{-}\right]$was higher post-supplementation compared to presupplementation in the HiN-LoT $(233 \pm 127$ vs. $1183 \pm 625 \mu \mathrm{M})$ and HiN-HiT $(171 \pm 107$ vs. $941 \pm 532 \mu \mathrm{M})$ conditions $(P<0.001)$, but not the LoN-LoT $(289 \pm 220$ vs. $192 \pm 118 \mu \mathrm{M})$ and LoN-HiT $(283 \pm 249$ vs. $177 \pm 123 \mu \mathrm{M})$ conditions $(P>0.05$; Figure 2$)$. The postsupplementation salivary $\left[\mathrm{NO}_{2}^{-}\right]$values were also higher in the HiN-LoT and HiN-HiT conditions compared to both the LoN-LoT and LoN-HiT conditions $(P<0.001)$. However, salivary $\left[\mathrm{NO}_{2}^{-}\right]$was higher post-supplementation in the HiN-LoT condition compared to the HiN-HiT condition $(P<0.05$; Figure 2$)$. The change in the pre-to-post-supplementation plasma $\left[\mathrm{NO}_{2}{ }^{-}\right]$was not different between the HiN-LoT and HiN-HiT conditions $(P>0.05)$, but there was a trend $(P=0.09)$ for a greater increase in pre-to-post-supplementation salivary $\left[\mathrm{NO}_{2}{ }^{-}\right]$in the HiN-LoT condition compared to the HiN-HiT condition.

\subsection{Blood pressure}

The systolic, diastolic and mean arterial blood pressures across the four experimental conditions are illustrated in figure 3. Systolic blood pressure was not different pre- and postsupplementation in the LoN-LoT (119 \pm 7 vs. $119 \pm 8$ mmHg), LoN-HiT (118 \pm 5 vs. $117 \pm 8$ mmHg) and HiN-HiT (119 \pm 6 vs. $119 \pm 7$ mmHg) conditions $(P>0.05)$, but was lower postsupplementation in the HiN-LoT condition (118 \pm 6 vs. $115 \pm 5$ mmHg; $P<0.05$; Figure 3 ). Diastolic blood pressure was not different pre- and post-supplementation in the LoN-LoT (66 
\pm 5 vs. $64 \pm 5$ mmHg), LoN-HiT (65 \pm 5 vs. $63 \pm 5$ mmHg), HiN-LoT (63 \pm 5 vs. $64 \pm 5$ mmHg) and HiN-HiT (64 \pm 4 vs. $64 \pm 6$ mmHg) conditions $(P>0.05)$. Similarly, mean arterial pressure was not different pre- and post-supplementation in the LoN-LoT (83 \pm 4 vs. $82 \pm 5$ mmHg), LoN-HiT (83 \pm 5 vs. $81 \pm 5$ mmHg), HiN-LoT (82 \pm 4 vs. $81 \pm 4$ mmHg) and HiN-HiT (83 \pm 3 vs. $83 \pm 6 \mathrm{mmHg}$ ) conditions $(P>0.05)$. The lowering in systolic blood pressure in the HiN-LoT condition was not correlated with the increase in salivary $\left[\mathrm{NO}_{2}^{-}\right](r=$ 0.08; $P>0.05)$. Moreover, there was no correlation between the differences in systolic blood pressure and salivary $\left[\mathrm{NO}_{2}^{-}\right]$post smoothie ingestion between the HiN-LoT condition and the LoN-LoT $(r=-0.02 ; P>0.05)$ and HiN-HiT $(r=0.06 ; P>0.05)$ conditions.

\section{DISCUSSION}

The important novel finding from this study was that co-ingestion of $\mathrm{NO}_{3}^{-}$-rich and $\mathrm{SCN}^{-}$-rich vegetables blunted the increase in salivary $\left[\mathrm{NO}_{2}{ }^{-}\right]$and the lowering of systolic blood pressure compared to the same portion of $\mathrm{NO}_{3}{ }^{-}$-rich vegetables ingested without $\mathrm{SCN}^{-}$-rich vegetables. The ingestion of vegetables low in both $\mathrm{NO}_{3}{ }^{-}$and $\mathrm{SCN}^{-}$, and low in $\mathrm{NO}_{3}{ }^{-}$but high in $\mathrm{SCN}^{-}$, did not impact plasma and salivary $\left[\mathrm{NO}_{3}^{-}\right]$and $\left[\mathrm{NO}_{2}^{-}\right]$or blood pressure responses. These results may have a potentially important public health message by suggesting that consuming $340 \mathrm{~g}$ of green vegetables, a dose within the recommended daily intake of fruit and vegetables $[3,24]$, evokes disparate effects on blood pressure dependent on the composition of the vegetables consumed. Specifically, it appears that blood pressure is lowered following the acute consumption of $\mathrm{NO}_{3}{ }^{-}$-rich vegetables without co-ingestion of $\mathrm{SCN}^{-}$-rich vegetables, but not after consumption of vegetables rich in $\mathrm{SCN}^{-}$and low in $\mathrm{NO}_{3}{ }^{-}$or when $\mathrm{NO}_{3}{ }^{-}$-rich and $\mathrm{SCN}^{-}$-rich vegetables are co-ingested. Our findings may have implications for finessing dietary guidelines aimed at enhancing cardiovascular health, particularly since current 
nutritional guidelines do not differentiate between low- and high- $\mathrm{NO}_{3}{ }^{-}$vegetable consumption $[3,4]$.

When the cell membranes of glucosinolate-rich plants are damaged, as occurs during mastication and during the blending procedures used to prepare the vegetable smoothie beverages administered in this study, glucosinolates are presented to myrosinase and subsequently hydrolysed to form $\mathrm{SCN}^{-}[23,24]$. Therefore, our observation of increased salivary and plasma [SCN$\left.{ }^{-}\right]$after consuming a glucosinolate-rich Brassica vegetable beverage in the LoN-HiT and HiN-HiT conditions is likely a function of myrosinase-catalyzed glucosinolate hydrolysis, and is consistent with previous reports of increased serum [ $\left.\mathrm{SCN}^{-}\right]$ after the consumption of Brassica vegetables [20]. In addition, and also consistent with previous studies, ingestion of $\mathrm{NO}_{3}{ }^{-}$-rich vegetables in the HiN-LoT and HiN-HiT conditions increased salivary and plasma $\left[\mathrm{NO}_{3}{ }^{-}\right]$and $\left[\mathrm{NO}_{2}{ }^{-}\right][8,13,14,17,26]$.

Salivary $\left[\mathrm{SCN}^{-}\right]$was lowered post supplementation compared to pre supplementation in the HiN-LoT condition consistent with previous observations [17] and with the notion that $\mathrm{NO}_{3}{ }^{-}$ and $\mathrm{SCN}^{-}$compete for a common salivary transporter $[16,17]$. However, in contrast with our hypothesis, salivary $\left[\mathrm{NO}_{3}{ }^{-}\right]$increased by a similar magnitude in the HiN-LoT and HiN-HiT conditions despite increased salivary and plasma $\left[\mathrm{SCN}^{-}\right]$in the latter compared to the former. This finding also conflicts with our previous observation that the increase in salivary $\left[\mathrm{NO}_{3}{ }^{-}\right]$ after $\mathrm{NO}_{3}{ }^{-}$ingestion was lower in smokers, who exhibited elevated plasma and salivary [SCN${ }^{-}$ ], compared to non-smokers [17]. These conflicting findings are likely attributable to greater differences in salivary $(+1164 \mu \mathrm{M})$ and plasma $(+22 \mu \mathrm{M})\left[\mathrm{SCN}^{-}\right]$between the smokers and non-smokers in the control condition of our previous study [17] compared to the mean change in salivary (+ $356 \mu \mathrm{M})$ and plasma $(+9 \mu \mathrm{M})\left[\mathrm{SCN}^{-}\right]$after consuming the two HiT beverages 
administered in the current study. Therefore, the findings in the present study suggest that increasing dietary $\mathrm{SCN}^{-}$intake, via the consumption of glucosinolate-rich vegetables, is unlikely to perturb salivary $\mathrm{NO}_{3}{ }^{-}$uptake at doses within the recommended daily fruit and vegetable consumption guidelines [3,25]. However, whilst the increase in salivary $\left[\mathrm{NO}_{3}{ }^{-}\right]$ was similar in the HiN-LoT and HiN-HiT conditions, the increase in salivary $\left[\mathrm{NO}_{2}{ }^{-}\right]$above baseline tended $(P=0.09)$ to be higher in the HiN-LoT condition compared to the HiN-HiT condition and the post-supplementation salivary $\left[\mathrm{NO}_{2}^{-}\right]$was higher in the HiN-LoT condition compared to the HiN-HIT condition. This suggests that, at the lower exposure rates applied in the current study, $\mathrm{SCN}^{-}$has the potential to impede the reduction of $\mathrm{NO}_{3}{ }^{-}$to $\mathrm{NO}_{2}{ }^{-}$in the oral cavity, or to catalyze $\mathrm{NO}_{2}{ }^{-}$degradation, rather than interfering with salivary $\mathrm{NO}_{3}{ }^{-}$uptake, as was observed at higher $\mathrm{SCN}^{-}$exposure rates in our recent smoking study [17]. The lower salivary $\left[\mathrm{NO}_{2}{ }^{-}\right]$in the HiN-HiT condition compared to the HiN-LoT condition might be linked to $\mathrm{SCN}^{-}$-mediated activation of myeloperoxidase (MPO), which oxidizes $\mathrm{NO}_{2}^{-}$to nitrogen dioxide $\left(\mathrm{NO}_{2}\right)$ [31]. In addition, MPO catalyses the oxidation of chloride $\left(\mathrm{Cl}^{-}\right)$to hypochlorite $\left(\mathrm{OCl}^{-}\right)$[32] which can react with $\mathrm{SCN}^{-}$to form hypothiocyanite (OSCN$\left.{ }^{-}\right)$[33], a potent oral antimicrobial agent [34]. $\mathrm{OSCN}^{-}$can also be produced from $\mathrm{SCN}^{-}$through the activity of salivary peroxidase (SPO) [35]. Therefore, the increase in salivary [ $\left.\mathrm{SCN}^{-}\right]$in the HiN-HiT condition might have activated MPO and SPO resulting in increased synthesis of the antimicrobial species, $\mathrm{OSCN}^{-}$[34], and a corresponding blunting of the rate of $\mathrm{NO}_{3}{ }^{-}$reduction to $\mathrm{NO}_{2}{ }^{-}$by the oral $\mathrm{NO}_{3}{ }^{-}$reducing bacteria $[13,14]$, compared to the HiN-LoT condition.

Systolic blood pressure was lowered in the HiN-LoT condition but not the LoN-LoT, LoNHiT and HiN-HiT conditions in this study, consistent with our hypotheses. This $3 \mathrm{mmHg}$ reduction in systolic blood pressure in the HiN-LoT condition is consistent with the lowering of systolic blood pressure after the consumption of $\mathrm{NO}_{3}{ }^{-}$-rich spinach [36,37], rocket [27], 
beetroot [11] or a mixture of $\mathrm{NO}_{3}{ }^{-}$-rich vegetables [8]. The magnitude by which blood pressure is lowered in these studies has potential clinical relevance having been associated with a lower incidence of future cardiovascular events [38]. It should also be acknowledged that systolic blood pressure has been reported to be lowered to a greater extent after ingesting $8 \mathrm{mmol}$ compared to $4 \mathrm{mmol}$ of $\mathrm{NO}_{3}{ }^{-}$(the same dose as administered in the current study in the $\mathrm{NO}_{3}{ }^{-}$-rich smoothies) when administered in the form of $\mathrm{NO}_{3}{ }^{-}$-rich beetroot juice [26]. Therefore, while it is likely that we could have observed a greater fall in systolic blood pressure with a greater $\mathrm{NO}_{3}{ }^{-}$dose, the requirements to combine different combinations of $\mathrm{NO}_{3}{ }^{-}$-rich, $\mathrm{SCN}^{-}$-rich, $\mathrm{NO}_{3}^{-}$-low and $\mathrm{SCN}^{-}$-low vegetables, and to not exceed the recommended daily fruit and vegetable intake of $400 \mathrm{~g} \cdot \mathrm{day}^{-1}[3,25]$ restricted our ability to administer a higher $\mathrm{NO}_{3}{ }^{-}$dose in the current study.

The lowering of blood pressure after the consumption of $\mathrm{NO}_{3}{ }^{-}$-rich vegetables has been attributed to increased circulating plasma $\left[\mathrm{NO}_{2}{ }^{-}\right][11,13,14,17,26,39,40]$, which can impact vascular function directly [41] or through the $\mathrm{O}_{2}$-independent reduction of $\mathrm{NO}_{2}^{-}$to $\mathrm{NO}$ production [42]. These changes in blood pressure after $\mathrm{NO}_{3}{ }^{-}$ingestion might be linked to increased classical NO-cyclic guanosine monophosphate (cGMP) signalling [39] or changes in renal physiology [43]. Therefore, the lack of change in systolic blood pressure in the LoNLoT and LoN-HiT conditions is likely a function of a lack of increase in plasma $\left[\mathrm{NO}_{2}^{-}\right]$in these conditions. However, plasma $\left[\mathrm{NO}_{2}{ }^{-}\right]$was increased by a similar magnitude in the HiNLoT and HiN-HiT conditions, but blood pressure was only lowered in the former. Although plasma $\left[\mathrm{NO}_{2}{ }^{-}\right]$was increased to a similar extent in the HiN-LoT and HiN-HiT conditions, the increase in salivary $\left[\mathrm{NO}_{2}^{-}\right]$was greater in the HiN-LoT condition. The increased salivary $\left[\mathrm{NO}_{2}{ }^{-}\right]$in the HiN-LoT condition would have been expected in increase $\mathrm{NO}_{2}{ }^{-}$delivery to the stomach, where the acidic $\mathrm{pH}$ facilitates the chemical reduction of $\mathrm{NO}_{2}{ }^{-}$to $\mathrm{NO}$ and a number 
of reactive nitrogen intermediates (RNI) including S-nitrosothiols (RSNO) [44]. It has recently been reported that the antihypertensive effect of oral $\mathrm{NO}_{2}{ }^{-}$administration is closely associated with plasma [RSNO], but can be dissociated from plasma [ $\left.\mathrm{NO}_{2}{ }^{-}\right][45,46]$. Therefore, whilst plasma $\left[\mathrm{NO}_{2}^{-}\right]$was not different between the HiN-LoT and HiN-HiT conditions, it is possible that the total circulating [RSNO] pool was greater in the HiN-LoT condition leading to a lower blood pressure in this condition compared to the HiN-HiT condition.

There is evidence that $\mathrm{SCN}^{-}$can lower the acidity of the gastric juice [47]. Combined with a potential lowering in gastric $\mathrm{NO}_{2}{ }^{-}$delivery, this might have contributed to a lowered gastric RSNO formation and passage into the circulation, and explained the lack of change in systolic blood pressure in the HiN-HiT condition and the lowering of systolic blood pressure in the HiN-LoT condition. However, since $\mathrm{SCN}^{-}$has been reported to aid NO synthesis in the stomach $[44,48]$, which through subsequent oxidation and autoxidation reactions might lead to the synthesis of RSNO [44,49], and since RSNO was not determined in the current study, further research is required to assess how different combinations of vegetables with varying $\mathrm{NO}_{3}{ }^{-}$and $\mathrm{SCN}^{-}$contents influences circulating [RSNO] and blood pressure. Moreover, the lowering of systolic blood pressure and the increase in salivary $\left[\mathrm{NO}_{2}{ }^{-}\right]$in the HiN-LoT condition, and the differences in systolic blood pressure and salivary $\left[\mathrm{NO}_{2}{ }^{-}\right]$post smoothie ingestion between the HiN-LoT condition and the LoN-LoT and HiN-HiT conditions were not correlated in the current study. Accordingly, the link between the greater reduction of blood pressure and increase in salivary $\left[\mathrm{NO}_{2}^{-}\right]$, and by extension stomach $\mathrm{NO}_{2}^{-}$delivery, in the HiN-LoT condition compared to the HiN-HiT is unclear and in need of further research. It should also be acknowledged that, although the $\mathrm{NO}_{3}{ }^{-}$and $\mathrm{SCN}^{-}$content of the smoothies administered in the current study was quantified and controlled, we cannot exclude the 
possibility that other nutrients differed between the smoothies and influenced systolic blood pressure either independently or synergistically with $\mathrm{NO}_{3}{ }^{-}$or $\mathrm{NO}_{2}{ }^{-}$. For example, ascorbic acid and polyphenols [50-52] can aid the reduction of $\mathrm{NO}_{2}{ }^{-}$to $\mathrm{NO}$ in the stomach which might have influenced our systolic blood pressure results. Further research is required to resolve the underlying mechanisms for a lowering of systolic blood pressure in the HiN-LoT condition but not the HiN-HiT condition.

Although blood pressure was not improved in the LoN-HiT and HiN-HiT conditions in this study, glucosinolate-rich vegetables possess anti-cancer properties [53, 54] and their consumption may have other benefits, including a reduction in death from atherosclerotic vascular disease [55]. As such, consumption of glucosinolate-rich vegetables should certainly not be avoided, but further research is required to assess the longer-term and wider health implications of consuming different combinations of vegetables. Moreover, since some cooking methods would denature myrosinase [22], and therefore the potential for $\mathrm{SCN}^{-}$ ingestion, it is unclear whether these findings can be reproduced if glucosinolate-rich vegetables are cooked prior to consumption.

In conclusion, the acute consumption of vegetables high in $\mathrm{NO}_{3}{ }^{-}$and low in $\mathrm{SCN}^{-}$, lowered systolic blood pressure in association with increased plasma and salivary $\left[\mathrm{NO}_{3}{ }^{-}\right]$and $\left[\mathrm{NO}_{2}{ }^{-}\right]$. However, when the same portion of high $\mathrm{NO}_{3}{ }^{-}$vegetables was co-ingested with high $\mathrm{SCN}^{-}$ vegetables the lowering of blood pressure was abolished and the increase in salivary $\left[\mathrm{NO}_{2}{ }^{-}\right]$ was attenuated. Plasma and salivary $\left[\mathrm{NO}_{3}^{-}\right]$and $\left[\mathrm{NO}_{2}^{-}\right]$were not increased and systolic blood pressure was not lowered after consuming vegetables low in $\mathrm{NO}_{3}{ }^{-}$and high $\mathrm{SCN}^{-}$or low in both $\mathrm{NO}_{3}{ }^{-}$and $\mathrm{SCN}^{-}$. These results suggest that green vegetables are not uniform in their potential to improve blood pressure and that $\mathrm{NO}_{3}{ }^{-}$-rich vegetables can lower blood pressure 
when consumed with vegetables low, but not high, in $\mathrm{SCN}^{-}$. Therefore, it appears that the potential of green vegetables to improve blood pressure, at portion sizes (340 g) within the recommended daily fruit and vegetable intake guidelines, is dependent on the nutritional composition of the vegetables consumed. These findings might have implications for improving public health by helping to refine nutritional guidelines aimed at improving cardiovascular health and lowering the risk of cardiovascular disease morbidity. 


\section{REFERENCES}

[1] Laslett, L. J.; Alagona, P. Jr.; Clark, B. A. $3^{\text {rd }}$; Drozda, J .P .Jr.; Saldivar, F.; Wilson, S. R, Poe, C.; Hart, M. The worldwide environment of cardiovascular disease: prevalence, diagnosis, therapy, and policy issues: a report from the American College of Cardiology. J Am Coll Cardiol. 60:S1-S49; 2012.

[2] Appel, L. J.; Moore, T. J.; Obarzanek, E.; Vollmer, W. M.; Svetkey, L. P.; Sacks, F. M.; Bray, G. A.; Vogt, T. M.; Cutler, J. A.; Windhauser, M. M,; Lin, P.H.; Karanja, N. A clinical trial of the effects of dietary patterns on blood pressure. DASH Collaborative Research Group. N Engl J Med. 336:1117-1124; 1997.

[3] NHS Choices. Why 5 a Day? $2013 . \quad$ Internet: http://www.nhs.uk/Livewell/5ADAY/Pages/5ADAYhome.aspx (accessed 25 ${ }^{\text {th }}$ August 2015).

[4] EUFIC. Fruit and vegetable consumption in Europe - do Europeans get enough? 2012. Internet: http://www.eufic.org/article/en/expid/Fruit-vegetable-consumption-Europe/ (accessed 25 ${ }^{\text {th }}$ August 2015).

[5] Bazzano, L. A.; He, J.; Ogden, L. G.; Loria, C. M.; Vupputuri, S.; Myers, L.; Whelton, P. K. Fruit and vegetable intake and risk of cardiovascular disease in US adults: the first National Health and Nutrition Examination Survey Epidemiologic Follow-up Study. Am J Clin Nutr. 76:93-99; 2002.

[6] Bazzano, L. A.; Serdula, M. K.; Liu, S. Dietary intake of fruits and vegetables and risk of cardiovascular disease. Curr Atheroscler Rep. 5:492-499; 2003.

[7] Gaziano, J. M.; Manson, J. E.; Branch, L. G.; Colditz, G. A.; Willett, W. C.; Buring, J. E. A prospective study of consumption of carotenoids in fruits and vegetables and decreased cardiovascular mortality in the elderly. Ann Epidemiol. 5:255-260; 1995.

[8] Ashworth, A.; Mitchell, K,; Blackwell, J. R.; Vanhatalo, A.; Jones, A. M. High-nitrate vegetable diet increases plasma nitrate and nitrite concentrations and reduces blood pressure in healthy women. Public Health Nutr. 16:1-10; 2015.

[9] Joshipura, K. J.; Ascherio, A.; Manson, J. E.; Stampfer, M. J,; Rimm, E. B.; Speizer, F. E.; Hennekens, C. H.; Spiegelman, D.; Willett, W. C. Fruit and vegetable intake in relation to risk of ischemic stroke. JAMA. 282:1233-1239; 1999.

[10] Joshipura, K. J.; Hu, F. B.; Manson, J. E.; Stampfer, M. J.; Rimm, E. B.; Speizer, F. E.; Colditz, G.; Ascherio, A.; Rosner, B.; Spiegelman, D.; Willet, W.C. The effect of fruit and vegetable intake on risk for coronary heart disease. Ann Intern Med. 134:1106-1114; 2001.

[11] Webb, A. J.; Patel, N.; Loukogeorgakis, S.; Okorie, M.; Aboud, Z.; Misra, S.; Rashid, R.; Miall, P.; Deanfield, J.; Benjamin, N.; MacAllister, R.; Hobbs, A. J.; Ahluwalia, A. Acute blood pressure lowering, vasoprotective, and antiplatelet properties of dietary nitrate via bioconversion to nitrite. Hypertension. 51:784-790; 2008.

[12] Weitzberg, E.; Lundberg, J. O. Novel aspects of dietary nitrate and human health. Annu Rev Nutr. 33:129-159; 2013. 
[13] Govoni, M.; Jansson, E. A.; Weitzberg, E,; Lundberg, J. O. The increase in plasma nitrite after a dietary nitrate load is markedly attenuated by an antibacterial mouthwash. Nitric Oxide. 19:333-337; 2008.

[14] Woessner, M.; Smoliga, J. M.; Tarzia, B.; Stabler, T.; Van Bruggen, M.; Allen, J. D. A stepwise reduction in plasma and salivary nitrite with increasing strengths of mouthwash following a dietary nitrate load. Nitric Oxide. 54:1-7; 2016.

[15] Duncan, C.; Li, H.; Dykhuizen, R.; Frazer, R.; Johnston, P.; MacKnight, G.; Smith, L.; Lamza, K.; McKenzie, H.; Batt, L.; Kelly, D.; Golden, M.; Benjamin, N.; Leifert, C. Protection against oral and gastrointestinal diseases: importance of dietary nitrate intake, oral nitrate reduction and enterosalivary nitrate circulation. Comp Biochem Physiol A Physiol. 118:939-948; 1997.

[16] Edwards, D. A.; Fletcher, K.; Rowlands, E. N. Antagonism between perchlorate, iodide, thiocyanate, and nitrate for secretion in human saliva; analogy with the iodide trap of the thyroid. Lancet. 266:498-499; 1954.

[17] Bailey, S. J.; Blackwell, J. R.; Wylie, L. J.; Holland, T.; Winyard, P. G.; Jones, A. M. Improvement in blood pressure after short-term inorganic nitrate supplementation is attenuated in cigarette smokers compared to non-smoking controls. Nitric Oxide. 61:29-37; 2016.

[18] Hord, N. G.; Tang, Y.; Bryan, N. S. Food sources of nitrates and nitrites: the physiologic context for potential health benefits. Am J Clin Nutr. 90:1-10; 2009.

[19] Lidder, S.; Webb, A. J. Vascular effects of dietary nitrate (as found in green leafy vegetables and beetroot) via the nitrate-nitrite-nitric oxide pathway. Br J Clin Pharmacol. 75:677-96; 2013.

[20] Olea F, Parras P. Determination of serum levels of dietary thiocyanate. J Anal Toxicol 1992; 16:258-260.

[21] Bhattacharjee, A.; Chandra, A. K.; Malik, T. Goitrogenic content of common vegetables in Sub-Himalayan Tarai region of Eastern Uttar Pradesh, International Journal of Medical and Health Sciences. 1:32-38; 2012.

[22] Verkerk, R.; Schreiner, M.; Krumbein, A.; Ciska, E.; Holst, B.; Rowland, I.; De Schrijver, R.; Hansen, M.; Gerhäuser, C.; Mithen. R.; Dekker, M. Glucosinolates in Brassica vegetables: the influence of the food supply chain on intake, bioavailability and human health. Mol Nutr Food Res. 53:S219; 2009.

[23] Angelino, D.; Dosz, E. B.; Sun, J.; Hoeflinger, J. L.; Van Tassell, M. L.; Chen, P.; Harnly, J. M.; Miller, M. J.; Jeffery, E. H. Myrosinase-dependent and -independent formation and control of isothiocyanate products of glucosinolate hydrolysis. Front Plant Sci. 6:831; 2015.

[24] Newman, R. M.; Hanscom, Z.; Kerfoot, W. C. The watercress glucosinolate-myrosinase system: a feeding deterrent to caddisflies, snails and amphipods. Oecologia. 92:1-7; 1992. 
[25] WHO. Increasing fruit and vegetable consumption to reduce the risk of noncommunicable diseases. 2016.2 Internet: http://www.who.int/elena/titles/fruit_vegetables_ncds/en/ (accessed $22^{\text {nd }}$ September 2016).

[26] Wylie, L. J.; Kelly, J.; Bailey, S. J.; Blackwell, J. R.; Skiba, P. F.; Winyard, P. G,; Jeukendrup, A. E.; Vanhatalo, A.; Jones, A. M. Beetroot juice and exercise: pharmacodynamic and dose-response relationships. J Appl Physiol. 115:325-336; 2013.

[27] Velasco, P.; Cartea, M. E.; Gonzalez, C.; Vilar, M.; Ordas, A. Factors affecting the glucosinolate content of kale (Brassica oleracea acephala group). J Agric Food Chem. 55:955962; 2007.

[28] Ysart, G,; Clifford, R.; Harrison, N. Monitoring for nitrate in UK-grown lettuce and spinach. Food Addit Contam. 16:301-306; 1999.

[29] Fletcher, J. R.; Law, S. J.; Walters, A. H. Effect of cooking on the nitrate levels in vegetables. Nutr Health. 5:61-3; 1987.

[30] Tsuge, K.; Kataoka, M.; Seto, Y. Cyanide and Thiocyanate Levels in Blood and Saliva of Healthy Adult Volunteers. J. Health Sci. 46:343-350; 2000.

[31] van der Vliet, A.; Eiserich, J. P.; Halliwell, B.; Cross, C. E.; Formation of reactive nitrogen species during peroxidase-catalyzed oxidation of nitrite. A potential additional mechanism of nitric oxide-dependent toxicity. J Biol Chem. 272:7617-7625; 1997.

[32] Arnhold, J.; Monzani, E,; Furtmueller, P. G.; Zederbauer, M.; Casella, L.; Obinger, C. Kinetics and thermodynamics of halide and nitrite oxidation by mammalian heme peroxidases. Eur J Inorg Chem. 19:3801-3811; 2006.

[33] Ashby, M. T.; Carlson, A. C.; Scott, M. J. Redox buffering of hypochlorous acid by thiocyanate in physiologic fluids. J Am Chem Soc. 126:15976-15977; 2004.

[34] Ashby, M. T. Inorganic chemistry of defensive peroxidases in the human oral cavity. J Dent Res. 87:900-914; 2008.

[35] Pruitt, K. M.; Mansson-Rahemtulla, B.; Baldone, D. C.; Rahemtulla, F. Steady-state kinetics of thiocyanate oxidation catalyzed by human salivary peroxidase. Biochemistry. 27:240-245; 1099.

[36] Jovanovski, E.; Bosco, L.; Khan, K.; Au-Yeung, F.; Ho, H.; Zurbau, A.; Jenkins, A. L.; Vuksan, V. Effect of Spinach, a High Dietary Nitrate Source, on Arterial Stiffness and Related Hemodynamic Measures: A Randomized, Controlled Trial in Healthy Adults. Clin Nutr Res. 4:160-167; 2015.

[37] Jonvik, K. L.; Nyakayiru, J,; Pinckaers, P. J.; Senden, J. M.; van Loon, L. J.; Verdijk, L. B. Nitrate-Rich Vegetables Increase Plasma Nitrate and Nitrite Concentrations and Lower Blood Pressure in Healthy Adults. J Nutr. 146:986-993; 2016. 
[38] He, F. J.; MacGregor, G. A. How far should salt intake be reduced? Hypertension. 42:1093-1099; 2003.

[39] Kapil, V.; Milsom, A. B.; Okorie, M.; Maleki-Toyserkani, S.; Akram, F.; Rehman, F.; Arghandawi, S.; Pearl, V.; Benjamin, N.; Loukogeorgakis, S.; Macallister, R.; Hobbs, A.J.; Webb, A.J.; Ahluwalia, A. Inorganic nitrate supplementation lowers blood pressure in humans: role for nitrite-derived NO. Hypertension. 56:274-281; 2010.

[40] Larsen, F. J.; Ekblom, B.; Sahlin, K.; Lundberg, J. O.; Weitzberg, E. Effects of dietary nitrate on blood pressure in healthy volunteers. N Engl J Med. 355:2792-2793; 2006.

[41] Bryan, N. S.; Fernandez, B. O.; Bauer, S. M.; Garcia-Saura, M. F.; Milsom, A. B.; Rassaf, T.; Maloney, R. E.; Bharti, A.; Rodriguez, J.; Feelisch, M. Nitrite is a signaling molecule and regulator of gene expression in mammalian tissues. Nat Chem Biol. 1:290-297; 2005.

[42] van Faassen, E. E.; Bahrami, S.; Feelisch, M.; Hogg, N.; Kelm, M.; Kim-Shapiro, D. B.; Kozlov, A. V.; Li, H.; Lundberg, J. O.; Mason, R.; Nohl, H.; Rassaf, T.; Samouilov, A.; Slama-Schwok, A.; Shiva, S.; Vanin, A. F.; Weitzberg, E.; Zweier, J.; Gladwin, M.T. Nitrite as regulator of hypoxic signaling in mammalian physiology. Med Res Rev. 29:683-741; 2009.

[43] Gao, X.; Yang, T.; Liu, M.; Peleli, M.; Zollbrecht, C.; Weitzberg, E.; Lundberg, J. O.; Persson, A. E.; Carlström, M. NADPH oxidase in the renal microvasculature is a primary target for blood pressure-lowering effects by inorganic nitrate and nitrite. Hypertension. 65:161-170; 2015.

[44] Lundberg, J. O.; Weitzberg, E.; Cole, J. A,; Benjamin, N. Nitrate, bacteria and human health. Nat Rev Microbiol. 2:593-602; 2004.

[45] Pinheiro, L. C.; Amaral, J. H.; Ferreira, G. C,; Portella, R. L.; Ceron, C. S.; Montenegro, M. F.; Toledo, J. C. Jr.; Tanus-Santos, J. E. Gastric S-nitrosothiol formation drives the antihypertensive effects of oral sodium nitrite and nitrate in a rat model of renovascular hypertension. Free Radic Biol Med. 87:252-262; 2015.

[46] Montenegro, M. F.; Sundqvist, M.L.; Larsen, F.J.; Zhuge, Z.; Carlström, M.; Weitzberg, E.; Lundberg, J. O. Blood Pressure-Lowering Effect of Orally Ingested Nitrite Is Abolished by a Proton Pump Inhibitor. Hypertension. 69:23-31; 2017.

[47] Davenport, H. W.; Fisher, R. B. The mechanism of the secretion of acid by the gastric mucosa. Am J Physiol. 129:505-514; 1940.

[48] Iijima, K.; Fyfe, V,; McColl, K. E. Studies of nitric oxide generation from salivary nitrite in human gastric juice. Scand J Gastroenterol. 38:246-252; 2003.

[49] Möller, M. N.; Li, Q.; Lancaster, J. R. Jr.; Denicola. A. Acceleration of nitric oxide autoxidation and nitrosation by membranes. IUBMB Life. 59:243-248; 2007.

[50] Gago, B.; Lundberg, J. O.; Barbosa, R. M.; Laranjinha, J. Red wine-dependent reduction of nitrite to nitric oxide in the stomach. Free Radic Biol Med. 43:1233-1242; 2007. 
[51] Peri, L,; Pietraforte, D.; Scorza, G.; Napolitano, A.; Fogliano, V.; Minetti, M. Apples increase nitric oxide production by human saliva at the acidic $\mathrm{pH}$ of the stomach: a new biological function for polyphenols with a catechol group? Free Radic Biol Med. 39:668-681; 2005.

[52] Rocha, B. S,; Gago, B.; Barbosa, R. M.; Laranjinha. J. Dietary polyphenols generate nitric oxide from nitrite in the stomach and induce smooth muscle relaxation. Toxicology. 265:41-48; 2009.

[53] Herr, I.; Büchler, M. W. Dietary constituents of broccoli and other cruciferous vegetables: implications for prevention and therapy of cancer. Cancer Treat Rev. 36:377-383; 2010.

[54] Kapusta-Duch, J.; Kopeć, A.; Piatkowska, E.; Borczak, B.; Leszczyńska, T. The beneficial effects of Brassica vegetables on human health. Rocz Panstw Zakl Hig. 63:389-95; 2012.

[55] Blekkenhorst, L. C.; Bondonno, C. P.; Lewis, J. R.; Devine, A,; Zhu, K.; Lim, W. H.; Woodman, R. J.; Beilin, L. J.; Prince, R. L.; Hodgson, J. M. Cruciferous and Allium Vegetable Intakes are Inversely Associated With 15-Year Atherosclerotic Vascular Disease Deaths in Older Adult Women. J Am Heart Assoc. 6:pii: e006558; 2017. 


\section{Figure legends}

Figure 1. Plasma (upper panel) and salivary (lower panel) thiocyanate concentration ([SCN$\left.{ }^{-}\right]$) in the low nitrate low thiocyanate (LoN-LoT), low nitrate high thiocyanate (LoN-HiT), high nitrate low thiocyanate (HiN-LoT) and high nitrate high thiocyanate (HiN-HiT) vegetable smoothie conditions. Group mean $( \pm$ SEM) responses prior to vegetable smoothie ingestion are shown as open bars with responses following vegetable smoothie ingestion shown as filled bars. Individual responses to the vegetable smoothies are shown for each experimental condition as solid grey lines. * indicates that the post supplementation value was significantly different to the pre supplementation value within the same experimental condition $(P<0.01)$.

Figure 2. Plasma (panel A) and salivary (panel B) nitrate concentration ([ $\left.\left.\mathrm{NO}_{3}{ }^{-}\right]\right)$and plasma (panel C) and salivary (panel D) nitrite concentration $\left(\left[\mathrm{NO}_{2}^{-}\right]\right.$) in the low nitrate low thiocyanate (LoN-LoT), low nitrate high thiocyanate (LoN-HiT), high nitrate low thiocyanate (HiN-LoT) and high nitrate high thiocyanate (HiN-HiT) vegetable smoothie conditions. Group mean ( \pm SEM) responses prior to vegetable smoothie ingestion are shown as open bars with responses following vegetable smoothie ingestion shown as filled bars. Individual responses to the vegetable smoothies are shown for each experimental condition as solid grey lines. * indicates that the post supplementation value was significantly different to the pre supplementation value within the same experimental condition $(P<0.01)$. \# indicates that the post supplementation value was significantly different to the post supplementation value in the HiN-LoT condition $(P<0.05)$. 
Figure 3. Systolic (panel A), diastolic (panel B) and mean arterial (panel C) blood pressures in the low nitrate low thiocyanate (LoN-LoT), low nitrate high thiocyanate (LoN-HiT), high nitrate low thiocyanate (HiN-LoT) and high nitrate high thiocyanate (HiN-HiT) vegetable smoothie conditions. Group mean $( \pm$ SEM) responses prior to vegetable smoothie ingestion are shown as open bars with responses following vegetable smoothie ingestion shown as filled bars. Individual responses to the vegetable smoothies are shown for each experimental condition as solid grey lines. * indicates that the post supplementation value was significantly different to the pre supplementation value within the same experimental condition $(P<0.05)$. Please note that in panel A two participants had the same systolic blood pressure values before and after the ingestion of the HiN-LoT beverage so there are only 10 visible individual response lines for this condition. 